\title{
Association of recurrent pregnancy loss and anticardiolipin antibodies: prevalence and prognosis of subsequent pregnancy in women with recurrent pregnancy loss
}

\author{
Malathi Verabelly*, Swapnarani Seedipally
}

Department of Obstetrics and Gynecology, Mallareddy Institute of Medical Sciences, Hyderabad, Telangana, India

Received: 10 November 2017

Accepted: 25 November 2017

\section{*Correspondence:}

Dr. Malathi Verabelly,

E-mail: malathi1174@gmail.com

Copyright: () the author(s), publisher and licensee Medip Academy. This is an open-access article distributed under the terms of the Creative Commons Attribution Non-Commercial License, which permits unrestricted non-commercial use, distribution, and reproduction in any medium, provided the original work is properly cited.

\begin{abstract}
Background: Anticardiolipin antibodies (ACA) are found with increased prevalence in women with unexplained recurrent pregnancy loss but their impact on future pregnancy is not clearly known. Therefore, present study objective was to compare the prevalence of ACA in patients with recurrent pregnancy loss and normal healthy pregnant women.

Methods: This prospective observational study from 100 pregnant women attending the outpatient department of Obstetrics and Gynaecology were studied. Study included 50 pregnant women with a history of three or more consecutive unexplained pregnancy loss as a study group and 50 pregnant women with two or more live children with no history of any previous pregnancy loss as a control group. Exclusion criteria included cases with any uterine anomaly, uterine structural abnormalities, induced abortions, infections, systemic disease, Rh-ve pregnancy, coagulation disorders and personal or family history of thrombosis.

Results: Overall, 9 patients tested positive for ACA, of which one (2\%) patient was from the control group and remaining $8(16 \%)$ were from study group. Overall, $42(84 \%)$ patients had negative test for ACA in the study group and $49(98 \%)$ patients in the control group. The live birth rate among study group was only $34(68 \%)$ whereas all 50 $(100 \%)$ pregnant women in the control group.

Conclusions: The findings described here in demonstrate that, ACA -positive patients are also the primary predictor of adverse pregnancy outcome and obstetric complications. Therefore, the role of early detection of ACA in all pregnant women is very important to prevent foetal outcomes and obstetric complications.
\end{abstract}

Keywords: Anticardiolipin antibodies, Pre-eclampsia, Pregnancy, IUGR

\section{INTRODUCTION}

In this modern era of in vitro fertilization and genetically engineered babies, there are still certain conceptions which end before they reach maturity, causing great physical and mental agony to the parents. Recurrent pregnancy loss is traditionally defined as three or more consecutive miscarriages occurring before 20 weeks postmenstruation. ${ }^{1-3}$ Around $1 \%$ of fertile couples will experience recurrent early pregnancy losses. ${ }^{2}$ Recently it has been proved that most common etiological cause for recurrent pregnancy loss is alteration of the immunological status. According to Kutteh and Pasquarette (1995) 15\% of women with recurrent pregnancy loss had recognizable auto immune disorders. ${ }^{4}$ Many different immunological factors have been suggested for recurrent pregnancy loss but out of these, antiphospholipid antibody syndrome has strong 
association with recurrent pregnancy loss. The prevalence of Antiphospholipids antibodies (APA) in general antenatal population is about $2 \%$ compared with about $15 \%$ in women with recurrent miscarriage. The successful pregnancy rate is only $10-15 \%$ in untreated women with APS. ${ }^{5}$

According to Pattison, 59 all patients with lupus anticoagulant have anticardiolipin antibodies (ACA) but not all patients with anticardiolipin antibodies have lupus anticoagulant. ${ }^{6}$ Lynch et al reported that an elevated $\lg G$ ACA was the only APA to be significantly associated with fetal demise. ${ }^{7} \operatorname{lgG}$ anti cardiolipin antibodies are more specific for recurrent pregnancy loss. All women with a history of three or more early pregnancy losses should be offered a testing for lupus anticoagulant (LAC) and anticardiolipin antibodies (ACA), known collectively as antiphospholipid antibodies (APA), to exclude an antiphospholipid syndrome (APS) ${ }^{8}$

Several attempts have been made to quantify the impact of ACA on pregnancy outcome but only a limited number of these studies have been prospective. The patients included in the prospective studies have been recruited from very different populations: women with systemic lupus erythematosus, healthy women with low risk pregnancies, women with recurrent miscarriage or mixtures of these populations. ${ }^{7,9-13,15-17}$ In the prospective studies, the effect of ACA on live birth rate has been reported very differently, The different results in the prospective studies could partly be attributed to poorly standardized ACA tests reflected in a significant interlaboratory variation in the detection of ACA significant fluctuations of the antibody levels over time in the same patient and very different cut off levels. ${ }^{17-24}$

For an obstetrician who is treating patients with recurrent pregnancy loss, previous studies do not adequately answer the question: what are the prognostic value of an elevated ACA titre and the development of late pregnancy complications such as preeclampsia, low birth weight and preterm labour? Therefore, present study objective was to compare the prevalence of ACA in patients with recurrent pregnancy loss and normal healthy pregnant women and its association of complication and obstetric outcomes.

\section{METHODS}

This was a prospective observational study from 100 pregnant women between August 2016 to August 2017 attending the outpatient department of Obstetrics and Gynaecology at Mallareddy Institute of Medical Sciences, Hyderabad.

This study included 50 pregnant women with a history of three or more consecutive unexplained pregnancy loss as a study group and 50 pregnant women with two or more live children with no history of any previous pregnancy loss as a control group. Exclusion criteria included cases with any uterine anomaly, uterine structural abnormalities, induced abortions, infections, systemic disease, Rh-ve pregnancy, coagulation disorders and personal or family history of thrombosis.

First trimester ultrasound is done to ensure foetal viability and for accurate dating, later repeated every fourth weekly to monitor growth. If any suspicion of IUGR than colour Doppler is advised. As these women are at risk of late pregnancy complications such as intra uterine growth retardation preterm delivery, hypertension, abruption, so patient should be warned about them.

The study was conducted after all institutional ethics requirements were met. Blood samples were obtained from study participants after the pregnancy for anticardiolipin antibody (ACA) testing. ACA positive patients were identified by enzyme-linked immunosorbent assays (ELISA) technique. The tests were performed using commercially available ELISA, according to the manufacturer's instructions. ELISA test was again repeated after 6-8 weeks on first time positive.

Only those patients who showed two positive ACA on consecutive ELISA tests with an interval of 6-8 weeks are confirmed to be part of this study group. Anti cardiolipin antibodies are identified based on the immunoglobulin (Ig) $\mathrm{G}$ concentrations in the serum. The levels of ACA specific IgG greater than 12 phospholipid units (GPU) /ml are determined to be ACA positive patients. All antenatal checkups followed as per guidelines and screen for other risks associated with pregnancy and treated according.

The study was approved by the Institutional Ethics Committee Review Board- "Institutional Committee for Research on Human Subjects, written informed consent was obtained from all participants and all investigations were conducted according to the principles expressed in the

The primary outcome measure was the prevalence of ACA positive in patients with recurrent pregnancy loss compared to healthy pregnant women. Secondary outcome measures were the fetal outcomes (live birth, abortion, still birth and intra uterine death [IUD]) in the ACA positive compared to ACA negative patients. Similarly, obstetric outcome (preeclampsia, preterm labour and intra uterine growth restriction [IUGR]) and obstetric complications (lower segment caesarean section [LSCS]) associated with ACA.

The data were analysed irrespective to the trimester. The diagnostic sensitivity and specificity of the study group (recurrent pregnancy loss) was calculated and compared in the healthy controls. The association between ACA positive occurrences with fetal outcomes, obstetric outcomes and obstetric complications were assessed and expressed as mean and percentage. 


\section{RESULTS}

The characteristics of study patients and controls are summarized in Table 1.

Table 1: Demographic and baseline characters.

\begin{tabular}{|c|c|c|}
\hline & $\begin{array}{l}\text { Study group } \\
N=50\end{array}$ & $\begin{array}{l}\text { Control } \\
\text { group } \mathbf{N}=\mathbf{5 0}\end{array}$ \\
\hline & n $(\%)$ & n $(\%)$ \\
\hline \multicolumn{3}{|l|}{ Age } \\
\hline$<20$ & $3(6 \%)$ & $7(14 \%)$ \\
\hline $21-25$ & $28(56 \%)$ & $25(50 \%)$ \\
\hline $26-29$ & $17(34 \%)$ & $15(30 \%)$ \\
\hline $31-35$ & $2(4 \%)$ & $3(6 \%)$ \\
\hline \multicolumn{3}{|l|}{ Socio economic status } \\
\hline Low & $31(62 \%)$ & $34(68 \%)$ \\
\hline Middle & $17(34 \%)$ & $15(30 \%)$ \\
\hline High & $2(4 \%)$ & $1(2 \%)$ \\
\hline \multicolumn{3}{|l|}{ VDRL } \\
\hline Reactive & $1(2 \%)$ & 0 \\
\hline Non reactive & $49(98 \%)$ & $50(100 \%)$ \\
\hline \multicolumn{3}{|l|}{ Platelet count } \\
\hline$<1,50,000 /$ microliter & $5(10 \%)$ & 0 \\
\hline$\geq 1,50,000 /$ microliter & $45(90 \%)$ & $50(100 \%)$ \\
\hline
\end{tabular}

Both patients and controls had comparable age groups and socioeconomic status. While the platelet count was lower in $10 \%$ of patients and $2 \%$ of VDRL positive in the study group.

\section{Prevalence of ACA in recurrent pregnancy loss}

The prevalence rates of the ACA detected in the different groups are detailed in Table 2.

Table 2: Anticardiolipin antibodies (ACA).

\begin{tabular}{|c|c|c|c|c|}
\hline & \multicolumn{2}{|c|}{$\begin{array}{l}\text { Study Group } \\
\mathrm{N}=50\end{array}$} & \multicolumn{2}{|c|}{$\begin{array}{l}\text { Control Group } \\
\mathbf{N}=\mathbf{5 0}\end{array}$} \\
\hline & $\begin{array}{l}\mathrm{ACA} \\
+\mathrm{Ve}\end{array}$ & $\begin{array}{l}\mathrm{ACA} \\
-\mathrm{Ve}\end{array}$ & $\begin{array}{l}\mathrm{ACA} \\
+\mathrm{Ve}\end{array}$ & $\begin{array}{l}\mathrm{ACA}- \\
\mathrm{Ve}\end{array}$ \\
\hline & $\mathrm{n}(\%)$ & $\mathrm{n}(\%)$ & $\mathrm{n}(\%)$ & $\mathrm{n}(\%)$ \\
\hline $\begin{array}{l}\text { ACA test } \\
\text { results }\end{array}$ & $8(16 \%)$ & $42(84 \%)$ & $1(2 \%)$ & $\begin{array}{l}49 \\
(98 \%)\end{array}$ \\
\hline $\begin{array}{l}\text { Platelet } \\
\text { Count }\end{array}$ & $\mathrm{n}=8$ & $\mathrm{n}=42$ & $\mathrm{n}=1$ & $\mathrm{n}=49$ \\
\hline $\begin{array}{l}<1,50,000 \\
\text { /microliter }\end{array}$ & $\begin{array}{l}1 \\
(12.5 \%)\end{array}$ & $\begin{array}{l}4 \\
(9.52 \%)\end{array}$ & 0 & 0 \\
\hline $\begin{array}{l}\geq 1,50,000 / \\
\text { microliter }\end{array}$ & $\begin{array}{l}7 \\
(87.5 \%)\end{array}$ & $\begin{array}{l}38 \\
(90.47 \%)\end{array}$ & $\begin{array}{l}1 \\
(100 \%)\end{array}$ & $\begin{array}{l}49 \\
(100 \%)\end{array}$ \\
\hline
\end{tabular}

Overall, 9 patients tested positive for ACA, of which one (2\%) patient was from the control group and remaining 8 (16\%) were from study group. Of the 8 (16\%) patients tested positive for ACA, one patient had platelet count below 150,000/microliter in ACA positive patients and 4 ACA positive patients were observed in negative for ACA test (Table 2).

Table 3: Complete obstetric complications and outcomes in all ACA positive patients.

\begin{tabular}{|c|c|c|c|c|c|c|c|}
\hline \multirow{2}{*}{ Age } & \multirow{2}{*}{ ML } & \multirow{2}{*}{ Obstetric formul } & \multirow{2}{*}{ Abortions } & Preeclampsia & \multirow{2}{*}{ IUGR } & \multirow{2}{*}{ Preterm labour } & \multirow{2}{*}{ Pregnancy outcome } \\
\hline & & & & EO LO & & & \\
\hline 26 & 7 & G4P2D2A1 & & 1 & -- & -- & IUD \\
\hline 19 & 3 & G3A2 & 1 & -- & -- & -- & $\begin{array}{l}\text { Missed Abortion, } 10 \text { weeks GA, } \\
\text { Instrumental evacuation done }\end{array}$ \\
\hline 25 & 6 & G4P1L1A2 & & -- & -- & -- & Still birth, Preterm delivery \\
\hline 29 & 10 & G5P1L1A3 & 1 & -- & -- & -- & $\begin{array}{l}\text { Spontaneous, abortion, } 8 \text { weeks } \\
\text { GA, Medical abortion done }\end{array}$ \\
\hline 24 & 6 & G3A2 & 1 & -- & -- & -- & $\begin{array}{l}\text { Missed Abortion, } 12 \text { weeks GA, } \\
\text { Instrumental evacuation done }\end{array}$ \\
\hline 28 & 10 & G4A3 & -- & -- & -- & -- & IUD \\
\hline 20 & 3 & G3A2 & -- & -- & 1 & -- & FTND live baby \\
\hline 32 & 12 & G5P3L1D2A1 & -- & -- & -- & -- & FT Emergency LSCS live baby \\
\hline
\end{tabular}

Overall, 42 (84\%) patients had negative test for ACA in the study group and $49(98 \%)$ patients in the control group. Of the 8 ACA +ve cases from the study group, only 2 gave live birth and remaining 6 could not make to live. Of these 6 cases had either, abortion or IUD or still birth (Table 3).

\section{Fetal outcomes}

Overall, the live birth rate among study group was only $34(68 \%)$ whereas all $50(100 \%)$ pregnant women in the control group gave live births. Furthermore, within the study group the incidence of abortions based on ACA test was $37.5 \%$ in ACA positive cases compared to $11.8 \%$ in ACA negative cases.

The intra uterine deaths (IUD) were $25 \%$ in ACA positive patients and $4.6 \%$ in ACA negative cases. It is more when compared to $0 \%$ in control group. Live birth rate among ACA positive cases is $25 \%$, compared to $76.1 \%$ in ACA negative cases (Figure 1). 


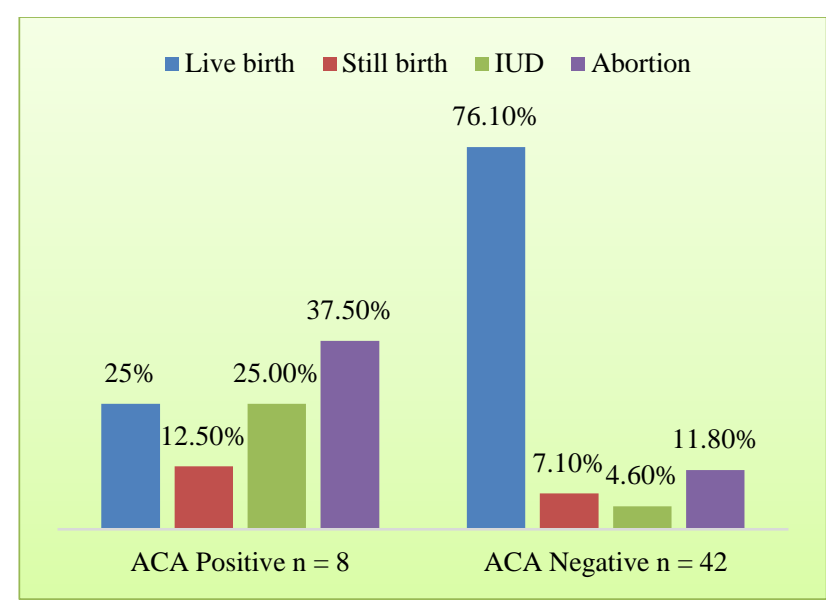

$\mathrm{IUD}=$ intra uterine death, $\mathrm{ACA}-\mathrm{ve}=$ anticardiolipin antibodies test negative, $\mathrm{ACA}+\mathrm{ve}=$ anticardiolipin antibodies positive

Figure 1: Fetal outcomes in ACA tested patients with recurrent pregnancy loss (within study group)

\section{Obstetric outcomes}

Obstetric complication of pre-eclampsia was most common in the study group compared to the control group. Similarly, intra uterine growth restriction was higher in the study group compared to the control group. Within the study group, ACA +ve patients had a higher rate of pre-eclampsia, especially early onset of preeclampsia. However, late onset of pre-eclampsia was common in the ACA -ve patients (Figure 2).

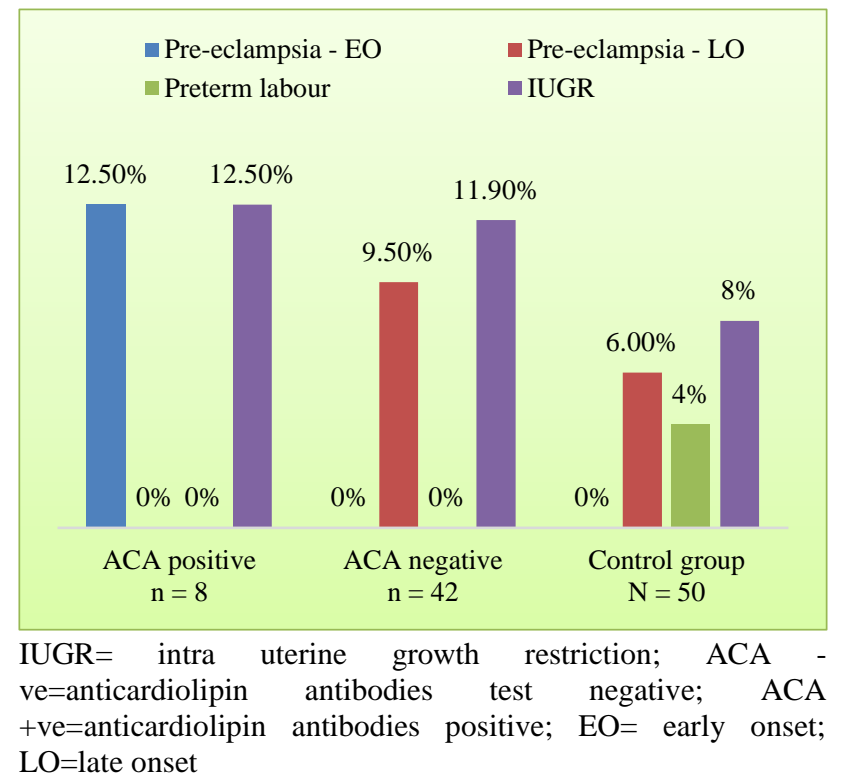

Figure 2: Obstetric complications.

\section{Correlation with ACA test and complications}

We also conducted retrospective analysis of previous pregnancies in association with the current status of ACA. Based on current status of ACA + ve cases, 23 foetuses could not continue to live birth. Most common obstetric complications in the mothers were preeclampsia and IUGR (Figure 3).

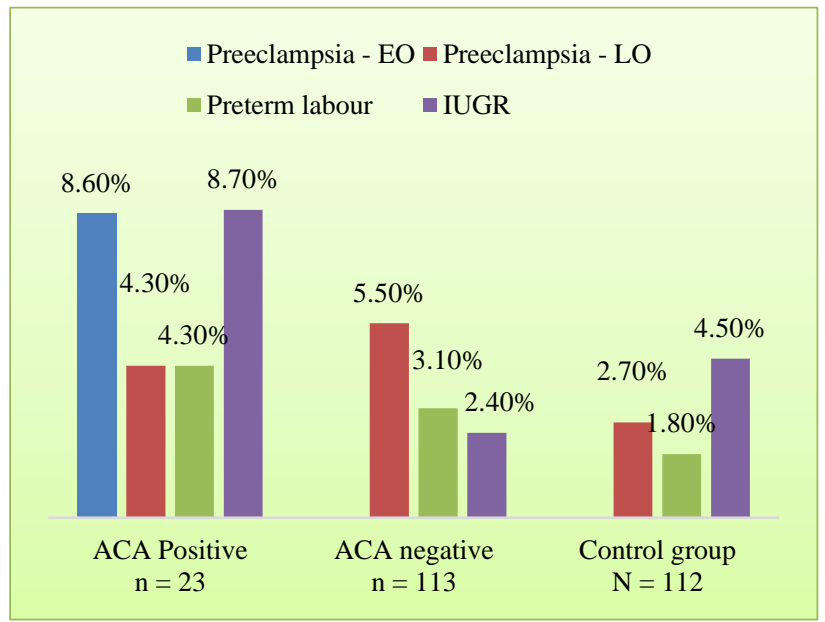

*number of previous pregnancies of 50 patients each from control and study groups, IUGR= intra uterine growth restriction; $\mathrm{ACA}-\mathrm{ve}=$ anticardiolipin antibodies test negative; $\mathrm{ACA}+\mathrm{ve}=$ anticardiolipin antibodies positive; $\mathrm{EO}=$ early onset; $\mathrm{LO}=$ late onset

Figure 3: Complications in previous pregnancies in study group and control group.

Of the 8 ACA positive pregnant women had 3 living children at the time of recruitment and had 20 pregnancy losses before the time of recruiting for this study. The different type of pregnancy loss is shown in the below Figure 4.

$\square$ Abortions $\square$ IUDs $\square$ Still birth/Early neonatal delivery

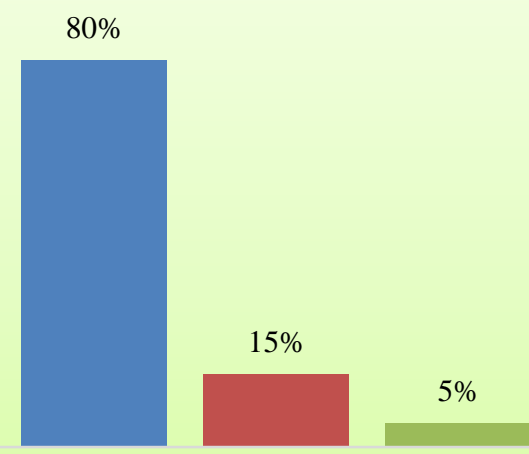

Type of pregnancy loss

Figure 4: Outcomes of previous pregnancies in the ACA +ve pregnant women.

\section{DISCUSSION}

The present prospective study provided the evidence that the ACA +ve patients during pregnancy have a high association of recurrent miscarriage especially in those who had a history of recurrent pregnancy loss. We also observed that the prognosis of a subsequent pregnancy 
following recurrent miscarriage is also dependent on ACA during or at the time of pregnancy. According to our study the prevalence of ACA in women with recurrent pregnancy loss was $16 \%$ when compared to $2 \%$ in normal obstetric population, which were comparable to the previous research. ${ }^{16,25}$

In this study, we have divided the overall study population data in to selected 3 groups of patients one with defined as control (without any pregnancy loss), second recurrent pregnancy loss clinical with ACA +ve patients and third was recurrent pregnancy loss clinical with ACA -ve patient's diagnosis.

The obstetric complications such as pre-eclampsia were higher in recurrent pregnancy loss group compared to the control group. Complications such as early onset preeclampsia were more common in ACA +Ve $12.5 \%$ women than in negative women $0 \%$. This was confirmed by previous report. ${ }^{26-28}$ In this study other complication like preterm labour, is not significantly associated with $\mathrm{ACA}+\mathrm{Ve}$ women compared to ACA - Ve women. The incidence of IUGR is more is in ACA +ve women $(12.5 \%)$ compared to only $8 \%$ in control group. In this study pregnancy outcome in ACA +ve women is associated with more number of abortions (37.5\%) and intra uterine deaths $(25 \%)$ compared to $0 \%$ in control group. In the present study Pregnancy outcome of live birth rate in ACA +ve cases is only $25 \%$ when compared to bad obstetric group as a whole (75\%) and $100 \%$ in control group. This shows significantly decreased live birth rate in ACA positive cases.

We observed that the prognosis of a subsequent pregnancy following recurrent pregnancy loss in ACA +ve women were similar in outcome, only 2 gave live birth and remaining 6 could not make to live. Therefore, it is evident from our study that with ACA +ve patients' recurrent pregnancy loss poses greater risk in the future fetal outcome. In the previous prospective studies, the effect of ACA on live birth rate has been reported comparable to our researcher, which has a negative impact on live birth. ${ }^{24,14,17}$

The limitations of the present study are its smaller sample size and single centre study; however, our study does not differ from previously reported studies on this topic.

\section{CONCLUSION}

The findings described herein demonstrate that, ACA positive patients are also the primary predictor of adverse pregnancy outcome and obstetric complications. Therefore, the role of early detection of ACA in all pregnant women is very important, especially who are at high risk and for pregnancy management and improving outcome. The limitations of the present study were its smaller sample size and single centre study; however, larger cohort studies are needed to conclude.

\section{ACKNOWLEDGMENTS}

Authors would like to thank Department of Obstetrics and Gynaecology, Mallareddy Institute of medical Sciences, Hyderabad, Telangana state, India.

\section{Funding: No funding sources}

Conflict of interest: None declared

Ethical approval: The study was approved by the Institutional Ethics Committee

\section{REFERENCES}

1. Stirrat GM. Recurrent miscarriage I: definition and epidemiology. Lancet. 1990;336(8716):673-5.

2. Berry CW, Bramabati B, Eskes TKAB, Exalto N, Fox H, Geraedts JPM et al. The Euro- Team Early Pregnancy (ETEP) protocol for recurrent miscarriage. Hum Reprod. 1995;10:1516-20.

3. Bricker L, Farquharson RG. Types of pregnancy loss in recurrent miscarriage: implications for research and clinical practice. Hum Reprod. 2002;17:1345-50.

4. Kutteh WH, Ermel LD. A clinical trial for the treatment of antiphospholipid antibody associated recurrent pregnancy loss with lower dose heparin and aspirin. Am J Reprod Immunol. 1996 Apr;35(4):4027.

5. Branch DW, Rodgers GM. Induction of endothelial cell tissue factor activity by sera from patients with antiphospholipid syndrome: a possible mechanism of thrombosis. Am J Obstet Gynecol. 1993 Jan;168(1 Pt 1):206-10.

6. Pattison N, Birdsall M, Chamley L, Lubbe W. Recurrent Foetal loss and the antiphospholipid syndrome, In: Recent Advances in Obstetrics and Gynecology, vol. 18, Ed. John Bonnar, Churchill Livingstone, London;1994

7. Lynch A, Marlar R, Murphy J, Davila G, Santos M, Rutledge J, Emlen W. Antiphospholipid antibodies in predicting adverse pregnancy outcome. A prospective study. Ann Intern Med. 1994;120:470-5.

8. Wilson WA1, Gharavi AE, Koike T, Lockshin MD, Branch DW, Piette JC et al. International consensus statement on preliminary classification criteria for definite antiphospholipid syndrome: report of an international workshop. Arthritis Rheum. 1999 Jul;42(7):1309-11.

9. Ginsberg JS, Brill-Edwards P, Johnston M, Denburg JA, Andrew M, Burrows RF et al. Relationship of antiphospholipid antibodies to pregnancy loss in patients with systemic lupus erythematosus: a crosssectional study. Blood. 1992;80:975-80.

10. Out HJ, Bruinse HW, Christianens GCML, Vliet MV, Groot PG, Nieuwenhuis HK et al. A prospective controlled multicenter study on the obstetric risks of pregnant women with antiphospholipid antibodies. Am J Obstet Gynecol. 1992;167:26-32.

11. Lockwood CJ, Romero R, Feinberg RF, Clyne LP, Coster B and Hobbins JC. The prevalence and 
biological significance of lupus anticoagulant and anticardiolipin antibodies in a general obstetric population. Am J Obstet Gynecol. 1989;160,439443.

12. Infante-Rivard C, David M, Gauthier R, Rivard GE. Lupus anticoagulants, anticardiolipin antibodies, and fetal loss. A case-control study. N Engl J Med. 1991 Oct 10;325(15):1063-6.

13. Pattison NS, Chamley LW, McKay EJ, Liggins GC, Butler WS. Antiphospholipid antibodies in pregnancy: prevalence and clinical associations. $\mathrm{Br} \mathrm{J}$ Obstet Gynaecol. 1993 Oct 1;100(10):909-13.

14. Yasuda M, Takakuwa K, Tokunaga A, Tanaka K. Prospective study of the association between anticardiolipin antibody and outcome of pregnancy. Obstet Gynecol. 1995;86:555-9.

15. Barbui T, Cortelazzo S, Galli M, Parazzini F, Radici E, Rossi E, Finazzi G. Antiphospholipid antibodies in early repeated abortions: A case-controlled study. Fertil Steril. 1988;50:589-92.

16. Parazzini F, Acaia B, Faden D, Lovotti M, Marelli G, Cortelazzo S. Antiphospholipid antibodies and recurrent abortion. Obstet Gynecol. 1991;77:854-8.

17. Rai RS, Clifford K, Cohen H, Regan L. High prospective fetal loss rate in untreated pregnancies of women with recurrent miscarriage and antiphospholipid antibodies. Hum Reprod. 1995b;10:3301-4.

18. Harris EN, Gharavi AE, Hughes GRV. Anticardiolipin antibody testing: The need for standardization. Arthritis Rheum. 1987b;30:835-7.

19. Peaceman AM, Silver RK, MacGregor SN, Socol ML. Interlaboratory variation in antiphospholipid antibody testing. Am J Obstet Gynecol. 1992 Jun 1;166(6):1780-7.

20. Roberts JM, Macara LM, Chalmers EA, Smith GCS. Inter-assay variation in antiphospholipid antibody testing. Br J Obstet Gynaecol. 2002;109:348-9.

21. Rai RS, Regan L, Clifford K, Pickering W, Dave M, Mackie L et al. Antiphospholipid antibodies and b2g1ycoprotein I in 500 women with recurrent miscarriage: Results of a comprehensive screening approach. Hum Reprod. 1995a;10:2001-5.
22. Donohoe S, Quenby S, Mackie I, Panal G, Farquharson R, Malia R et al. Fluctuations in levels of antiphospholipid antibodies and increased coagulation activation markers in normal and heparin-treated antiphospholipid syndrome pregnancies. Lupus. 2002;11:11-20.

23. Quenby SM, Farquharson RG. Predicting recurring miscarriage: what is important? Obstet Gynecol. 1993;82:132-8.

24. Tulppala M, Palo ST, Ramsay T, Miettinen A, Salonen R, Ylikorkala O. A prospective study of 63 couples with a history of recurrent spontaneous abortion: contributing factors and outcome of subsequent pregnancies. Hum Reprod. 1993;8:764770 .

25. Kumar KS, Jyothy A, Prakash MS, Rani HS, Reddy PP. Beta 2-glycoprotein I dependent anticardiolipin antibodies and lupus anticoagulant in patients with recurrent pregnancy loss. J Postgrad Med. 2002 JanMar;48(1):5-10.

26. Allen JY, Tapia-Santiago C, Kutteh WH. Antiphospholipid antibodies in patients with preeclampsia. Am J Reprod Immunol. 1996 Aug;36(2):81-5.

27. Moodley J, Bhoola V, Duursma J, Pudifin D, Byrne $\mathrm{S}$, Kenoyer DG. The association of antiphospholipid antibodies with severe early-onset pre-eclampsia. S Afr Med J. 1995;85(2):105-7.

28. Branch DW, Andres R, Digre KB, Rote NS, Scott JR. The association of antiphospholipid antibodies with severe preeclampsia. Obstet Gynecol. 1989;73(4):541-5.

Cite this article as: Verabelly M, Seedipally S. Association of recurrent pregnancy loss and anticardiolipin antibodies: prevalence and prognosis of subsequent pregnancy in women with recurrent pregnancy loss. Int J Reprod Contracept Obstet Gynecol 2018;7:74-9. 